OPEN ACCESS

Edited by: Bernhard Schaller, University of Southampton, UK

Reviewed by:

Thiago S. Moreira,

University of São Paulo, Brazil

Deoclecio Alves Chianca-Jr. Universidade Federal de Ouro Preto,

Brazil

*Correspondence: Dominga Lapi d.lapi@dfb.unipi.it

Specialty section: This article was submitted to Autonomic Neuroscience, a section of the journal Frontiers in Neuroscience

Received: 24 July 2016 Accepted: 03 October 2016 Published: 20 October 2016

Citation:

Lapi D, Scuri R and Colantuoni A (2016) Trigeminal Cardiac Reflex and

Cerebral Blood Flow Regulation.

Front. Neurosci. 10:470.

doi: 10.3389/fnins.2016.00470

\section{Trigeminal Cardiac Reflex and Cerebral Blood Flow Regulation}

\author{
Dominga Lapi ${ }^{1 *}$, Rossana Scuri ${ }^{2}$ and Antonio Colantuoni ${ }^{1}$ \\ ${ }^{1}$ Department of Clinical Medicine and Surgery, "Federico II" University Medical School, Naples, Italy, ${ }^{2}$ Department of \\ Translational Research on New Technologies in Medicine and Surgery, University of Pisa, Pisa, Italy
}

The stimulation of some facial regions is known to trigger the trigemino-cardiac reflex: the main stimulus is represented by the contact of the face with water. This phenomenon called diving reflex induces a set of reactions in the cardiovascular and respiratory systems occurring in all mammals, especially marine (whales, seals). During the immersion of the face in the water, the main responses are aimed at reducing the oxygen consumption of the organism. Accordingly reduction in heart rate, peripheral vasoconstriction, blood pooling in certain organs, especially the heart, and brain and an increase in blood pressure have been reported. Moreover, the speed and intensity of the reflex is inversely proportional to the temperature of the water: more cold the water, more reactions as described are strong. In the case of deep diving an additional effect, such as blood deviation, has been reported: the blood is sequestered within the lungs, to compensate for the increase in the external pressure, preventing them from collapsing. The trigeminal-cardiac reflex is not just confined to the diving reflex; recently it has been shown that a brief proprioceptive stimulation (10 min) by jaw extension in rats produces interesting effects both at systemic and cerebral levels, reducing the arterial blood pressure, and vasodilating the pial arterioles. The arteriolar dilation is associated with rhythmic diameter changes characterized by an increase in the endothelial activity. Fascinating the stimulation of trigeminal nerve is able to activate the nitric oxide release by vascular endothelial cells. Therefore, the aim of this review was to highlight the effects due to trigeminal cardiac reflex induced by a simple mandibular extension. Opposite effects, such as hypotension, and modulation of cerebral arteriolar tone, were observed, when these responses were compared to those elicited by the diving reflex.

\section{Keywords: trigeminal cardiac reflex, mandibular extension, pial arterioles, vasomotion, brain}

\section{INTRODUCTION}

In recent years several clinical studies allowed one to assert that the trigeminal cardiac reflex (TCR) is a clinical phenomenon characterized by hemodynamic perturbations, such as reduction in arterial hypotension, bradycardia, respiratory (apnea), and gastric changes (hypermobility). These effects are triggered by stimulation of any branch of the fifth cranial nerve along its course (Kumada et al., 1975, 1977; Schaller et al., 1999; Schaller, 2004, 2005; Schaller et al., 2009a).

It has been suggested that the TCR is due to sensory nerve endings of the trigeminal nerve. The neuronal signals, originated by these endings, are conducted to the sensory nucleus of the trigeminal nerve, via the Gasserian ganglion, forming the afferent pathway of the reflex arc (White and McRitchie, 1973; Schaller et al., 1999). 
This afferent pathway continues along the short internuncial nerve fibers in the reticular formation to connect with the efferent pathway in the motor nucleus of the vagus nerve. Several lines of experimental evidence demonstrate that trigeminally induced cardiovascular reflexes could be mediated initially in the trigeminal nucleus caudalis. Subsequently, the parabrachial nucleus, the rostral ventrolateral medulla oblongata, the dorsal medullary reticular field, and the paratrigeminal nucleus are involved in animal models (White and McRitchie, 1973; Schaller et al., 1999). Because the TCR involves all these structures, it was interesting to evaluate the effects exerted by TCR on the cerebral circulation, because hypotension, and bradycardia could induce cerebral blood flow reduction.

Experimental studies, carried out in rabbits, indicate that TCR represents an expression of a central neurogenic reflex leading to rapid cerebrovascular vasodilation, generated by excitation of oxygen-sensitive neurons in the rostral ventrolateral medulla oblongata (Campbell et al., 1994; Ichinohe et al., 1997; Sires et al., 1998; Schaller, 2004). However, these data have been detected only in the cortex. According to this physiological response, the adjustments of the systemic and cerebral circulations can divert blood to the brain or increase cerebral blood flow.

Several clinical observations indicate that TCR causes changes in cerebral cortex blood flow (White and McRitchie, 1973; Loewinger et al., 1987; Bainton et al., 1990; Kosaka et al., 2000; Burnstine, 2002; Schaller et al., 2007, 2009b). No data, however, have been reported about the influence of TCR on the cerebral blood flow in the short and long term follow up period after the reflex beginning.

\section{TCR EFFECT'S ON CEREBRAL BLOOD FLOW}

It is known that TCR occurs during both the peripheral and the central manipulations of the trigeminal nerve (Schaller, 2007). Brunelli et al. showed that a brief proprioceptive stimulation (10 $\mathrm{min}$ ) by jaw extension causes hypotension and bradycardia in humans (Brunelli et al., 2012).

Successively, Lapi et al. demonstrated that a single mandibular extension (ME), consisting in a submaximal rat mouth opening for $10 \mathrm{~min}$ by means of a dilator, is accompanied by an unusually prolonged reduction (about $3 \mathrm{~h}$ ) of heart rate (HR) and mean arterial blood pressure (MABP) (Lapi et al., 2013, 2014a). This effect was found to be associated with a characteristic and prolonged modulation of cerebral arteriolar tone. At first, vasoconstriction concomitant with the ME stimulus was observed; successively, a prolonged vasodilation occurred, lasting for $3 \mathrm{~h}$, during the entire experimental observation period (Lapi et al., 2013).

Although many aspects related to the underlying mechanisms remain to be explained, some of them are now clear. On one hand, it has been shown that these effects are abolished when the three peripheral trigeminal branches are bilaterally cut, indicating that they may be included among the so-called trigemino-cardiac reflexes (Lapi et al., 2013). These results are in agreement with the studies by Kumada and Schaller who observed that trigeminal nerve stimulations are accompanied by (brief) hypotensive and bradycardic responses in anesthetized rabbits and in humans during neurosurgical intervention, respectively (Kumada et al., 1977; Schaller, 2004; Schaller et al., 2007).

Furthermore, it was observed that these effects depend on the ME stimulation length, i.e., less prolonged and pronounced, when the ME lasted 5 min compared to $10 \mathrm{~min}$ stimulation. Finally, it has been shown that the initial brief vasoconstriction response involves an opioid-receptor mediated mechanism, because this response is abolished by the opioid-receptor antagonist naloxone. The subsequent prolonged vasodilation involves a nitric oxide mediated mechanism, because it was blunted by the nitric oxide synthase inhibitor $\left(\mathrm{L}_{-} \mathrm{N}^{\mathrm{G}}\right.$ Nitroarginine methyl ester: L-NAME) (Lapi et al., 2014b). A subsequent in vitro study, carried out by Lapi and coworkers, showed an increase in the neuronal nitric oxide synthase (nNOS) expression during and after $\mathrm{ME}$, unable to result in vasodilation during ME. However, an increase in the endothelial nitric oxide synthase (eNOS) expression, $2 \mathrm{~h}$ after ME, was demonstrated.

\section{TCR EFFECT'S ON CEREBRAL ARTERIOLAR TONE MODULATION}

It is interesting to note that the arterioles display rhythmic variations in diameter, termed vasomotion, triggered by smooth muscle cells; however, the endothelium is able to play a modulatory role on vessel tone (Bertuglia et al., 1999). Analyzing the arteriolar diameter changes on $30 \mathrm{~min}$ long-term tracings under baseline conditions and after $\mathrm{ME}$, it was possible to enhance the resolution of the low-frequency components, according to Stefanovska's results in humans (Stefanovska et al., 1999). The frequency components around 1.0, 0.3, $0.1,0.04 \mathrm{~Hz}$ have been related to the heart rate, respiration, intrinsic myogenic activity of vascular smooth muscle cells and neurogenic activity on the vessel wall, respectively. Moreover, the frequency component in the range $0.0095-0.021 \mathrm{~Hz}$ appears to be modulated by the vascular endothelium (Kvernmo et al., 1999; D'Addio et al., 2013).

The results by Lapi et al. demonstrate the pial arterioles undergo rhythmic diameter changes in sham-operated rats. In $30 \mathrm{~min}$ recordings six frequency components were detected: (1) ULF (endothelial activity NO-independent) $0.005-0.0095 \mathrm{~Hz}$, (2) VLF (endothelial activity NO-dependent): 0.0095-0.021 $\mathrm{Hz}$, (3) ILF (neurogenic activity): $0.021-0.052 \mathrm{~Hz}$, (4) LF (myogenic activity): $0.052-0.145 \mathrm{~Hz},(5) \mathrm{HF}$ (respiratory activity): $0.145-2.00 \mathrm{~Hz}$ and (6) VHF (heart beat): $2.500-4.000 \mathrm{~Hz}$ (Lapi et al., 2014a). This pattern was detected during the whole observation time (over $3 \mathrm{~h}$ ), while MABP (125 \pm $10 \mathrm{mmHg})$ and $\mathrm{HR}(330 \pm 25 \mathrm{bpm})$ remained unchanged (Figure 1A).

In rats submitted to $10 \mathrm{~min} \mathrm{ME}$, under baseline conditions MABP was $130 \pm 15 \mathrm{mmHg}$, HR was $325 \pm 30 \mathrm{bpm}(p=$ NS vs. sham operated rats) and rhythmic arteriolar oscillations were not different compared to those observed in sham operated 
A

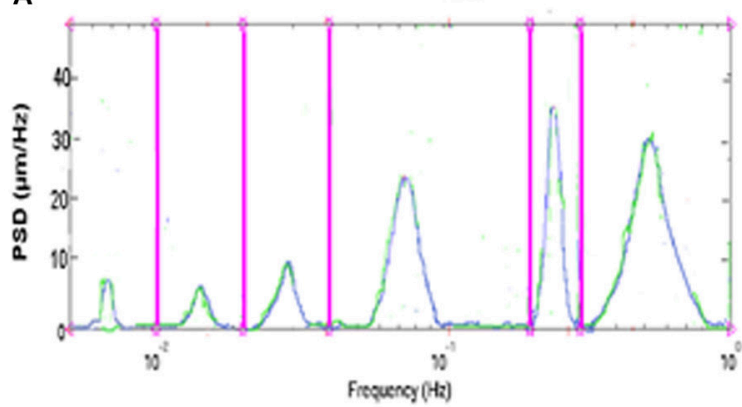

B

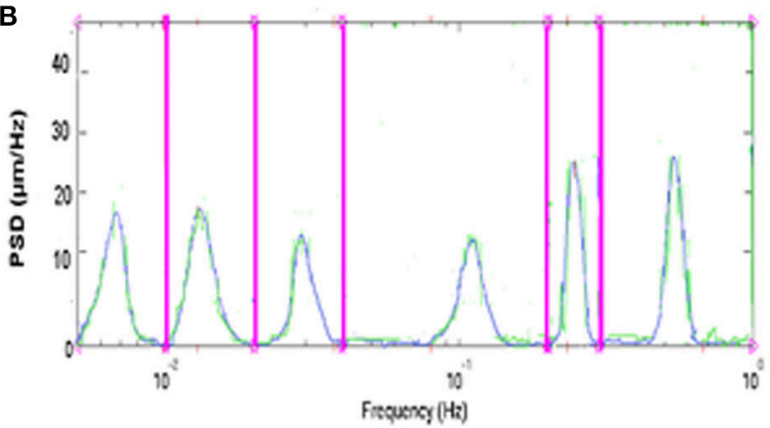

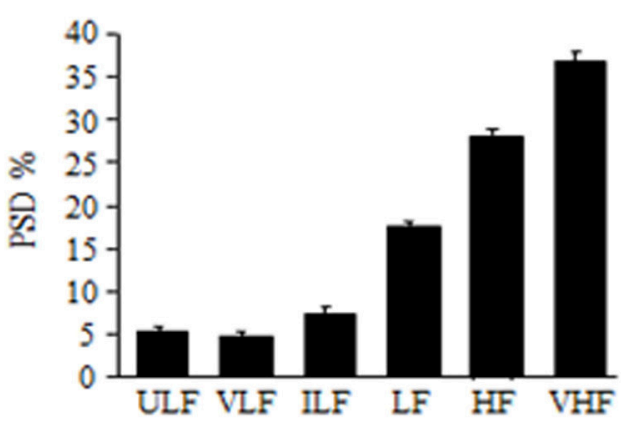

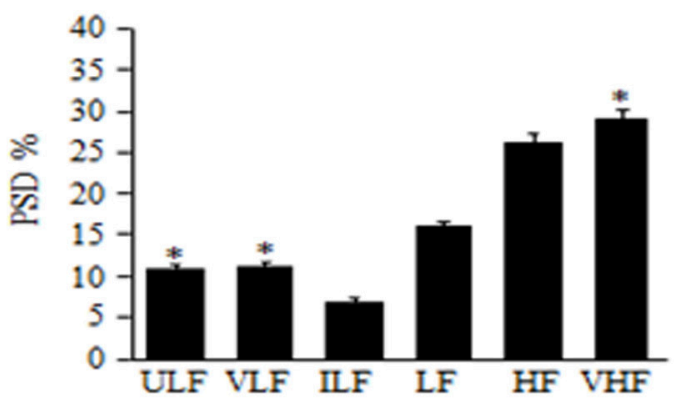

FIGURE 1 | Effects of mandibular extension on rhythmic diameter changes in pial arterioles (mean diameter: $30.0 \pm 2.5 \mu$ m). Rats subjected to ME, the rhythmic diameter changes (left) and the main corresponding frequency components (right), expressed as percent normalized power spectral density (PSD: $\mu \mathrm{m} 2 / \mathrm{Hz}$ ) were measured in baseline conditions (A) and during vasodilation (B). ME caused a significant increase of the ULF and VLF frequency components and a decrease of VHF component. ULF, ultra low frequency component; VLF, very low frequency component; ILF, intermediate frequency components; LF, low frequency component; $\mathrm{HF}$, high frequency component ; VHF, very high frequency component. *Significantly different from the baseline value.

rats (Lapi et al., 2014a). After ME, MAP, and HR decreased by $20.5 \pm 1.2$ and $23.0 \pm 0.8 \%$ of baseline, respectively; conversely, the amplitude of the first and second frequency components increased: ULF by $7.0 \pm 1.5 \%$ and VHF by $8.0 \pm$ $2.0 \%$ of baseline (Figure 1B). Concomitantly, the other frequency components decreased compared with those detected under baseline conditions. These effects lasted up to $3 \mathrm{~h}$ after ME (Lapi et al., 2013).

Therefore, a brief (10 min) and passive ME causes a significant and prolonged decrease in MABP and HR, accompanied by an increase in pial arteriolar diameter according to previously reported data (Lapi et al., 2013). Vasodilation is characterized by an increase in the spectral density of the lowest frequencies related to endothelial activity, ULF and VLF (ranges: 0.005$0.0095 \mathrm{~Hz}$ and $0.0095-0.021 \mathrm{~Hz}$, respectively).

$\mathrm{ME}$ appears to affect the mechanisms involved in the regulation of pial arteriolar tone for long time, likely facilitating the perfusion of cerebral tissue through a modulation of the rhythmic arteriolar diameter changes.

Up to day, the mechanisms whereby ME is accompanied by a prolonged reduction in blood pressure and heart rate remain uncertain. However, ME-induced hypotension may fall into the category of the so-called trigemino-cardiac reflexes extensively reviewed by Schaller (Schaller, 2007). TCR has been proposed to represent the expression of a neuroprotective central neurogenic reflex leading to rapid cerebrovascular vasodilatation in response to facial and nasal mucosal stimulation, such as during diving. Moreover, the reflex may be of potential relevance in brain injury states (Schaller, 2004). Finally, TCR induced by $\mathrm{ME}$ as well as the systemic responses, related to activation of vagal efferent discharge, affect the mechanisms involved in the regulation of pial arteriolar tone, increasing the endothelial activity, and facilitating the redistribution of cerebral blood flow supply.

In conclusion, these deep insights into cerebral hemodynamics changes during TCR could stimulate clinical trials and could suggest the development of suitable non-invasive devices, useful in the treatment of disease with impaired cerebral arteriolar tone.

\section{AUTHOR CONTRIBUTIONS}

DL: substantial contributions to the conception, analysis and interpretation of data for the work. DL, RS, AC: revising it critically for important intellectual content. AC: Final approval of the version to be published. 


\section{REFERENCES}

Bainton, R., Barnard, N., Wiles, J. R., and Brice, J. (1990). Sinus arrest complicating a bitemporal approach to the treatment of pan-facial fractures. Br. J. Oral Maxillofac. Surg. 28, 109-110. doi: 10.1016/0266-4356(90)90134-7

Bertuglia, S., Colantuoni, A., and Intaglietta, M. (1999). "Regulation of vascular tone and capillary perfusion," in Texbook of Angiology, ed J. B. Chan (New York, NY: Springer-Verlag), 439-454.

Brunelli, M., Coppi, E., Tonlorenzi, D., Del Seppia, C., Lapi, D., Colantuoni, A., et al. (2012). Prolonged hypotensive and bradycardic effects of passive mandibular extension: evidence in normal volunteers. Arch. Ital. Biol. 150, 231-237. doi: 10.4449/aib.v150i4.1420

Burnstine, M. A. (2002). Clinical recommendations for repair of isolated orbital floor fractures: an evidence-based analysis. Ophthalmology 109, 1207-1210. doi: 10.1016/S0161-6420(02)01057-6

Campbell, R., Rodrigo, D., and Cheung, L. (1994). Asystole and bradycardia during maxillofacial surgery. Anesth. Prog. 41, 13-16.

D'Addio, G., Cesarelli, M., Iuppariello, L., Lapi, D., and Colantuoni, A. (2013). "Effects of wavelets analysis on power spectral distributions," in Laser Doppler Flowmetry Time Series IFMBE Proceedings (Naples), 647-650.

Ichinohe, T., Agata, H., Aida, H., and Kaneko, Y. (1997). Cerebral cortex regional blood flow and tissue oxygen tension during the trigeminal depressor response in rabbits. J. Auton. Nerv. Syst. 66, 111-118. doi: 10.1016/S0165-1838(97) 00076-3

Kosaka, M., Asamura, S., and Kamiishi, H. (2000). Oculocardiac reflex induced by zygomatic fracture; a case report. J. Craniomaxillofac. Surg. 28, 106-109. doi: 10.1054/jcms.2000.0107

Kumada, M., Dampney, R. A., and Reis, D. J. (1975). The trigeminal depressor response: a cardiovascular reflex originating from the trigeminal system. Brain Res. 92, 485-489. doi: 10.1016/0006-8993(75)90335-2

Kumada, M., Dampney, R. A., and Reis, D. J. (1977). The trigeminal depressor response: a novel vasodepressor response originating from the trigeminal system. Brain Res. 119, 305-326. doi: 10.1016/0006-8993(77)90313-4

Kvernmo, H. D., Stefanovska, A., Kirkeboen, K. A., and Kvernebo, K. (1999). Oscillations in the human cutaneous blood perfusion signal modified by endothelium-dependent and endothelium-independent vasodilators. Microvasc. Res. 57, 298-309. doi: 10.1006/mvre.1998.2139

Lapi, D., Colantuoni, A., Del Seppia, C., Ghione, S., Tonlorenzi, D., Brunelli, M., et al. (2013). Persistent effects after trigeminal nerve proprioceptive stimulation by mandibular extension on rat blood pressure, heart rate and pial microcirculation. Arch. Ital. Biol. 151, 11-23. doi: 10.4449/aib.v151i1.1470

Lapi, D., Federighi, G., Fantozzi, M. P., Del Seppia, C., Ghione, S., Colantuoni, A., et al. (2014b). Trigeminocardiac reflex by mandibular extension on rat pial microcirculation: role of nitric oxide. PLOS ONE 12:e115767. doi: 10.1371/journal.pone.0115767

Lapi, D., Varanini, M., Gheser, F., Ghione, S., Del Seppia, C., Scuri, R., et al. (2014a). "Effects of mandibular extension on low-frequency components," in 8th Conference of the European Study Group on Cardiovascular Oscillations ESGCO Rat Pial Arteriolar Rhythmic Diameter Changes (Naples).

Loewinger, J., Cohen, M., and Levi, E. (1987). Bradycardia during elevation of a zygomatic arch fracture. J. Oral Maxillofac. Surg. 45, 710-711. doi: 10.1016/0278-2391(87)90315-6

Schaller, B. (2004). Trigeminocardiac reflex. A clinical phenomenon or a new physiological entity. J. Neurol. 251, 658-665. doi: 10.1007/s00415-004-0458-4

Schaller, B. (2005). Trigemino-cardiac reflex during transsphenoidal surgery for pintuary adenomas. Clin. Neurol. Neurosurg. 107, 468-474. doi: 10.1016/j.clineuro.2004.12.004

Schaller, B. J. (2007). Trigeminocardiac reflex. J. Neurosurg. 107, 243-244. doi: 10.3171/JNS-07/07/0243

Schaller, B., Cornelius, J. F., Prabhakar, H., Koerbel, A., Gnanalingham, K., Sandu, N., et al. (2009a). The trigemino-cardiac reflex: an update of the current knowledge. J. Neurosurg. Anesthesiol. 21, 187-195. doi: 10.1097/ANA.0b013e3181a2bf22

Schaller, B., Filis, A., Sandu, N., and Buchfelder, M. (2009b). Letter to the Editor: peripheral trigemino-cardiac reflex. Acta Neurochr. 151:1727. doi: 10.1007/s00701-009-0390-6

Schaller, B. J., Weigel, D., Filis, A., and Buchfelder, M. (2007). Trigemino-cardiac reflex during transsphenoidal surgery for pituitary adenomas: methodological description of a prospective skull base study protocol. Brain Res. 1149, 69-75. doi: 10.1016/j.brainres.2005.08.060

Schaller, B., Probst, R., Strebel, S., and Gratzl, O. (1999). Trigeminocardiac reflex during surgery in the cerebellopontine angle. J. Neurosurg. 90, 215-220. doi: 10.3171/jns.1999.90.2.0215

Sires, B. S., Stanley, R. B. Jr., and Levine, L. M. (1998). Oculocardiac reflex caused by orbital floor trapdoor fracture: an indication for urgent repair. Arch. Ophthalmol. 116, 955-956.

Stefanovska, A., Bracic, M., and Kvernmo, H. D. (1999). Wavelet analysis of oscillations in the peripheral blood circulation measured by laser Doppler technique. IEEE Trans. Biomed. Eng. 46, 1230-1239. doi: 10.1109/10. 790500

White, S. W., and McRitchie, R. J. (1973). Nasopharyngeal reflexes: integrative analysis of evoked respiratory and cardiovascular effects. Aust. J. Exp. Biol. Med. Sci. 51, 17-31. doi: 10.1038/icb. 1973.2

Conflict of Interest Statement: The authors declare that the research was conducted in the absence of any commercial or financial relationships that could be construed as a potential conflict of interest.

Copyright (C) 2016 Lapi, Scuri and Colantuoni. This is an open-access article distributed under the terms of the Creative Commons Attribution License (CC BY). The use, distribution or reproduction in other forums is permitted, provided the original author(s) or licensor are credited and that the original publication in this journal is cited, in accordance with accepted academic practice. No use, distribution or reproduction is permitted which does not comply with these terms. 